\begin{abstract}
Military Technical College
Kobry Elkobah

Cairo Egypt
\end{abstract}

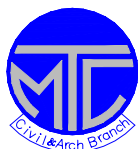

ICCAE

International Conference

On Civil \& Architecture

Engineering

\title{
NONLINEAR SEISMIC ANALYSIS OF BASE ISOLATED MDOF STRUCTURES
}

\author{
HUSSEIN MEGAHED ${ }^{1}$ AND ABDEL-MAGUID KHAFAGI ${ }^{2}$
}

\begin{abstract}
Seismic isolation elastomeric bearings in buildings and bridges have proven to be a very effective passive method for reducing earthquake-induced forces by lengthening the period of vibration of the original fixed base structure in conjunction with increasing the damping ratio. In the present study, four structures have been investigated using a selected set of actual strong earthquake time histories at the base. The time histories were scaled using an appropriate scaling method. The structures rang between two story (stiff) up to eight story (flexible) superstructures based on stiff soil. The isolation systems are described by ten different generic nonlinear hysteretic models, which are representative of wide range of elastomeric isolation systems. A computer program has been developed. It has the capability to implement the modeling of the various mechanisms of interest. The comparative results show a comprehensive seismic performance of base isolated structures. Finally, the isolated structures have been compared with the fixed base structures.
\end{abstract}

Keywords: Earthquake engineering, base isolation, elastomeric bearing, nonlinear analysis, time history.

\section{INTRODUCTION}

Seismic isolation is a relatively old concept that is rapidly gaining more acceptance in recent years as a great number of base isolated bearings has been developed after extensive experimental and linear and nonlinear analytical studies [1]. In practice, the only way to have both low floor accelerations and low interstory drifts during earthquakes can be accomplished by having isolated structures [2]. Using an effective isolation system can significantly reduce the costs of buildings and bridges. The isolation system can be appropriately designed to limit the nonlinear response down to the level of the isolation system leaving the superstructure to act as an elastic or nearly elastic system. Therefore, superstructure elements can be designed to withstand forces less than those resulted in same superstructures but based on fixed

\footnotetext{
${ }^{1}$ Associate Professor, Structural Engineering Department, Cairo University.

${ }^{2}$ Graduate Student, Structural Engineering Department, Cairo University.
} 
supports. Accordingly, this may justify the increased costs involved with the construction using base isolation. Overall, by taking into consideration the problems associated with facades, partitions, and other nonstructural elements following a great earthquake, the concept of using base isolation is an economical option for lower cost during the life age of many structures.

In a study by Kircher and Lashkari [3], a rigid superstructure based on a grid of 45 isolators with 31 different bilinear hysteretic properties was investigated. The isolation system properties covered the entire range of interest in seismic isolation, that is, effective periods of 1 to 4 seconds and effective damping of $6 \%$ to $39 \%$ of the critical damping. Later, Winters and Constantinou extended the study of Kircher and Lashkari to be applied on 1-story (stiff) and 8-story (flexible) superstructures based on a stiff and medium soil sites [4]. It was concluded that when the response spectrum analysis procedure is properly applied, the static and the response spectrum analysis procedures would lead to matching results with the mean of time history results for the bearing displacements and shear forces at the base of the building. However, the results of shear forces in the upper stories are under predicted.

Furthermore, the role of isolation damping was studied for moderate height base isolated buildings under the effect of eight real earthquakes [5]. It was observed that the choice of damping in isolators is crucial since damping large values may result in increased forces and accelerations as was previously acknowledged in reference [1]. In another study, a combined isolation system possessing the advantages of sliding and rubber bearings was investigated [6]. It was concluded that combined systems can significantly mitigate the nonlinear seismic response of both the structure and the isolation system.

Recently, Megahed and Khafagi studied five dissipation mechanisms using a set of actual strong earthquake time histories at the base of various combinations of two degree-offreedom (DOF) isolated structures [7]. A computer program has been developed using an efficient nonlinear algorithm which has the option of using either constant or variable integration time step in order to maintain the required accuracy particularly in sliding bearings. Therefore, it is intended in the present study to extend the earlier work to be applied on multi-degree-of-freedom (MDOF) buildings based on the isolation systems used previously by Winters and Constantinou through a nonlinear time history analysis.

\section{ISOLATED MDOF SYSTEM FORMULATION}

A brief description of the formulation of the base isolated MDOF buildings is presented as the following.

\section{Superstructure Modeling}

The superstructure is modeled as a full elastic two dimensional (2D) frame structure. Each joint is modeled with three degrees of freedom (two translations and one rotation in the superstructure plane). The stiffness matrix of the superstructure is assembled first. Within each floor, only one DOF (horizontal translation) at the center of mass is transformed, using the assumption of rigid floor diaphragm, to the frame DOF at the floor level as shown in Fig. 1(a). The remaining joint DOF's are eliminated by the static condensation before the superstructure stiffness is added to the total structural stiffness, as shown in Fig. 1(b). A comprehensive description of the lateral frame stiffness matrix assembly and static condensation can be found in reference [8]. The condensed superstructure mass matrix is a diagonal matrix with dimension equal to the number of floors. The eigenvalue analysis is performed to determine the eigenvalues and eigenvectors which are the frequencies and mode 
shapes in the fixed base condition. Then the superstructure damping matrix can be constructed using reasonably defined modal damping ratios along with the obtained eigenvalues as described in reference [8].

\section{Isolation System Modeling}

The isolation system is modeled with spatial distribution and explicit nonlinear force displacement characteristics of individual energy dissipation devices. The considered isolation elements can be one or a combination of the following: (i) linear elastic element; (ii) linear viscous element; (iii) hysteretic element for elastomeric bearings and steel dampers; (iv) hysteretic element for sliding bearings [9]. More details about the explicit characteristics used in the present study are provided in reference[7].

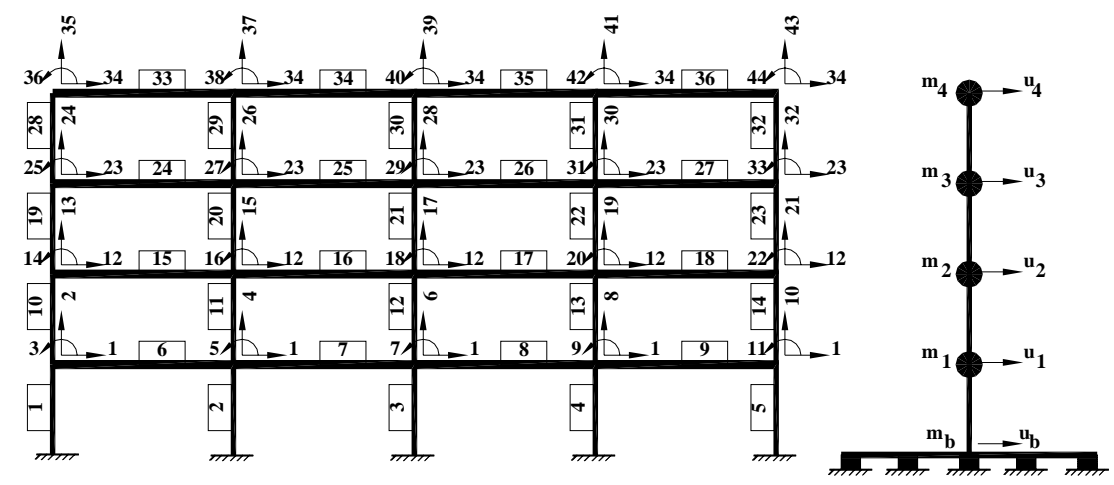

(a) Fixed Base Superstructure Model

(b) Global Model

Figure 1: Typical Modeling of a Four Story 2D Isolated Building

\section{Global System Assembly}

The condensed superstructure and the isolation system are combined to obtain the formulation of the global system assembly as shown in Fig. 1(b). The equation of motion of the global system can be represented in a matrix form as the following.

$[M]\{\ddot{U}\}+[C]\{\dot{U}\}+[K]\{U\}+\{F\}=-[M]\left\{U_{b}\right\} \ddot{u}_{g}$

where $[M],[C]$, and $[K]$ are the global mass, damping, and stiffness matrices, respectively.

$\ddot{u}_{\mathrm{g}}$ is the history of ground acceleration. The matrices and vectors of the above equation can be expressed as the following.

$$
\begin{aligned}
& {[M]=\left[\begin{array}{cc}
{\left[M_{s}\right]} & {\left[M_{s}\right]\left\{U_{b s}\right\}} \\
\left\{U_{b s}\right\}^{T}\left[M_{s}\right] & \left\{U_{b s}\right\}^{T}\left[M_{s}\right]\left\{U_{b s}\right\}+m_{b}
\end{array}\right],[C]=\left[\begin{array}{cc}
{\left[C_{s}\right]} & \{0\} \\
\{0\}^{T} & C_{b}
\end{array}\right],[K]=\left[\begin{array}{cc}
{\left[K_{s}\right]} & \{0\} \\
\{0\}^{T} & k_{b}
\end{array}\right],} \\
& \{F\}=\left\{\begin{array}{c}
\{0\} \\
P
\end{array}\right\},\left\{U_{b}\right\}=\left\{\begin{array}{c}
\{0\} \\
1
\end{array}\right\},\{U\}=\left\{\begin{array}{c}
\left.u_{s}\right\} \\
u_{b}
\end{array}\right\}
\end{aligned}
$$


where $\left[M_{s}\right],\left[C_{s}\right]$ and $\left[K_{s}\right]$ are the superstructure mass, damping and stiffness matrices, respectively. $\quad m_{b}$ is the mass of the base floor. $c_{b}$ is the total damping of the base linear viscous elements. $k_{b}$ is the total stiffness of the base linear elastic elements. $\left\{U_{b s}\right\}$ is the static displacement vector of the condensed superstructure when its base displaces by unity in the direction of the earthquake. $P$ is the total force mobilized in the nonlinear hysteretic elements of the isolation system. $\left\{u_{s}\right\}$ is the displacement vector of the condensed superstructure. $u_{b}$ is the displacement of the base floor relative to the base below the isolation system.

The above equations are solved using a successful nonlinear algorithm [7]. The time history of superstructure displacements and rotations and member forces of interest are computed by back substitution after the nonlinear time history analysis is computed.

\section{EARTHQUAKE GROUND MOTION RECORDS}

In the ATC-40 [10], two sets of 10 earthquake records each have been identified as suitable candidates for time history analysis. The records, after appropriate scaling, are suitable for time history analysis of buildings at all sites (except soft and very soft soil sites) for ground shaking of 0.2 or greater EPA (effective peak acceleration). In the present study, seven records of the second set are chosen. More details about the chosen records are available in reference [7]. The selected unscaled records have a variety of PGA values; all of them are more than $0.25 \mathrm{~g}$. In the present study, seismic zone 5 of the ECL 03 [11] was the only zone considered since it contains the highest seismicity. The effective PGA for seismic zone 5 is $0.25 \mathrm{~g}$. Consequently, scaling the records is necessary to insure that the response spectra be consistent with the seismic spectra under consideration.

On the other hand a scaling method using the PGV as reported by [4] was applied since it was considered more appropriate for an accurate representation of the amplitude and frequency content of ground motion at periods greater than 1.0 second. The records were scaled by specific factors such that the PGV of each one was equal to $30.0 \mathrm{~cm} / \mathrm{sec}$ for stiff soil sites. The mean pseudo acceleration response spectra for various damping ratios are shown in Fig. 2.

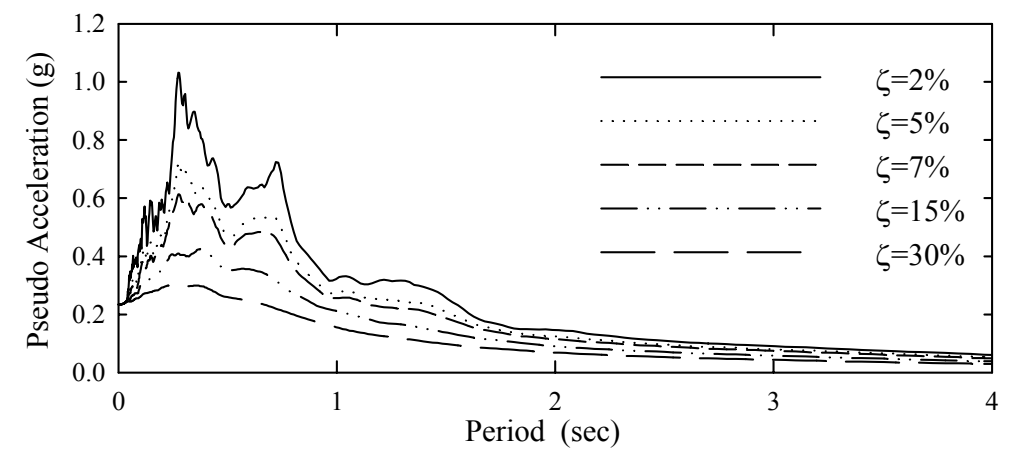

Figure 2: The Mean Pseudo Acceleration Response Spectra.

\section{ISOLATION SYSTEMS}

Most commercially available isolation systems can be reasonably well modeled by bilinear behavior. Therefore, the nonlinear force-deflection characteristics of the isolation systems 
used in the present study were modeled by bilinear hysteretic elements. Ten isolation systems were selected before to be applicable on stiff soils in the study of Winters and Constantinou study [4]. Each isolation system had a different characteristic strength or yield force $\left(Y_{F}\right)$, post yielding stiffness ratio $(\alpha)$ and different properties (effective period, stiffness and damping ratio) in order to create a set of isolation schemes that range from almost linear to highly nonlinear. It is expected that the isolated building models would represent the dynamic characteristics of a significant portion of feasible isolation schemes.

All isolation systems had a yield displacement, $D_{Y}$, equal to $1.27 \mathrm{~cm}$. Their nonlinear properties and equivalent linear properties are given in Table 1. All forces are normalized to structure weight $(W)$. The equivalent (effective) linear properties are based on the design displacement, $D$, and the maximum force, $F_{\max }$, as calculated by the static analysis procedure of SEAOC [12]. It may be seen that the properties of the analyzed isolation systems cover the period range of 1.5 to 3 seconds and the effective damping range of $6 \%$ to $39 \%$ of the critical Damping. Table 1 shows four groups I, II, III and IV. Each group has a certain value for effective period accompanied with various damping ratios.

Table 1: Properties of the Isolation Systems.

\begin{tabular}{|c|c|c|c|c|c|c|c|}
\hline \multirow{2}{*}{$\begin{array}{c}\text { Group } \\
\text { No }\end{array}$} & \multirow{2}{*}{$\begin{array}{l}\text { Isolation } \\
\text { System } \\
\text { Type } \\
\text { Number }\end{array}$} & \multicolumn{2}{|c|}{$\begin{array}{l}\text { Effective Linear } \\
\text { Properties }\end{array}$} & \multicolumn{2}{|c|}{ Design Parameters } & \multicolumn{2}{|c|}{$\begin{array}{c}\text { Parameters in Nonlinear } \\
\text { Analysis } \\
\end{array}$} \\
\hline & & $\begin{array}{c}\text { Period } \\
(\mathrm{sec})\end{array}$ & $\begin{array}{l}\text { Damping } \\
\text { Ratio(\%) }\end{array}$ & $\begin{array}{c}D \\
(\mathrm{~mm})\end{array}$ & $F_{\max } / W$ & $Y_{F} / W$ & $\alpha$ \\
\hline \multirow{3}{*}{ I } & 1 & 1.5 & 7 & 142 & 0.25 & 0.05 & 0.392 \\
\hline & 2 & 1.5 & 15 & 114 & 0.20 & 0.07 & 0.232 \\
\hline & 3 & 1.5 & 31 & 89 & 0.16 & 0.10 & 0.100 \\
\hline \multirow{3}{*}{ II } & 4 & 2.0 & 6 & 201 & 0.20 & 0.03 & 0.383 \\
\hline & 5 & 2.0 & 16 & 147 & 0.15 & 0.05 & 0.189 \\
\hline & 6 & 2.0 & 30 & 119 & 0.12 & 0.07 & 0.085 \\
\hline \multirow{2}{*}{ III } & 7 & 2.5 & 10 & 211 & 0.14 & 0.03 & 0.235 \\
\hline & 8 & 2.5 & 27 & 155 & 0.10 & 0.05 & 0.089 \\
\hline \multirow{2}{*}{ IV } & 9 & 3.0 & 16 & 226 & 0.10 & 0.03 & 0.139 \\
\hline & 10 & 3.0 & 39 & 163 & 0.07 & 0.05 & 0.040 \\
\hline
\end{tabular}

\section{PROGRAM MODELING}

A computer program has been recently developed to determine the seismic performance of a SDOF structure based on various energy dissipative mechanisms [7]. The computer program has been expanded in the present study to be applied on MDOF structure. The results of the program were compared with those obtained by the 3D-BASIS-M [13] and SAP2000 [14] and showed very good agreement. Furthermore, the developed program has the advantage of saving much time in the solution algorithm.

\section{PARAMETRIC STUDY}

The main goal of the present parametric study is to provide enough information about the efficiency of various elastomeric types on the seismic response of base isolated multi story structures and also to compare the results with those of the fixed base structures. Four superstructures models were used as typical representatives of two-story (B1), four-story (B2), six-story (B3) and eight-story (B4) moment resisting frames. All buildings consisted of four bays as shown in Fig. 3. The width of each bay is 6.0 meters and the height of each floor is 3.0 meters. The mass and stiffness of all floors were kept uniformly distributed for each building of interest satisfying the well known formula of $T=0.1 \mathrm{~N}$ where $T$ is the fundamental 
period and $N$ is the number of stories. Therefore, the fundamental periods of buildings $\mathrm{B} 1$, $\mathrm{B} 2, \mathrm{~B} 3$ and $\mathrm{B} 4$ are $0.2,0.4,0.6$, and $0.8 \mathrm{sec}$, respectively. The damping ratio was chosen equal to $5 \%$ of the critical for all superstructures. Analyses were performed on 44 superstructure/isolation system models (four superstructures B1, B2, B3 and B4 based on ten types of isolation systems and another one as fixed base) under the excitation of seven scaled actual earthquake ground motions.
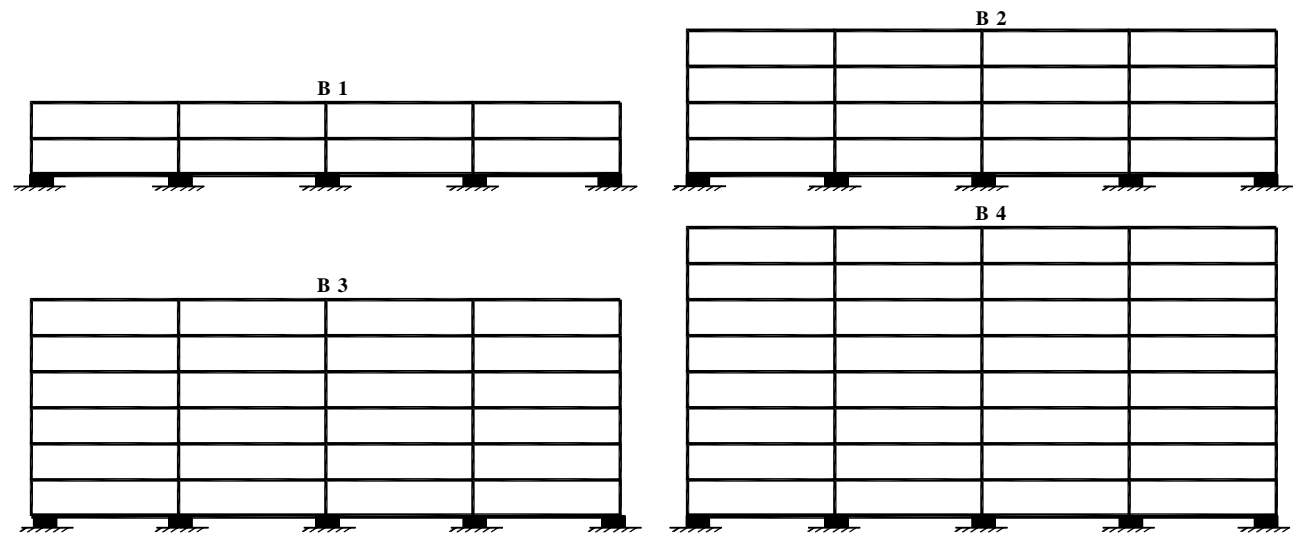

Figure 3: Sketch of Four Isolated Building Models

To show the capabilities of the program, the time history of some selected translation and rotation DOFs of the four-story building (B2) as previously defined in Fig. 1(a) are given in Fig. 4. The building was subjected to the scaled 1992, Cape Mendocino earthquake, Petrolia. The figure shows a comparison between the fixed base building results with those of the same building based on isolation number 7. It is quite obvious that the base isolated case gives significantly lower responses.

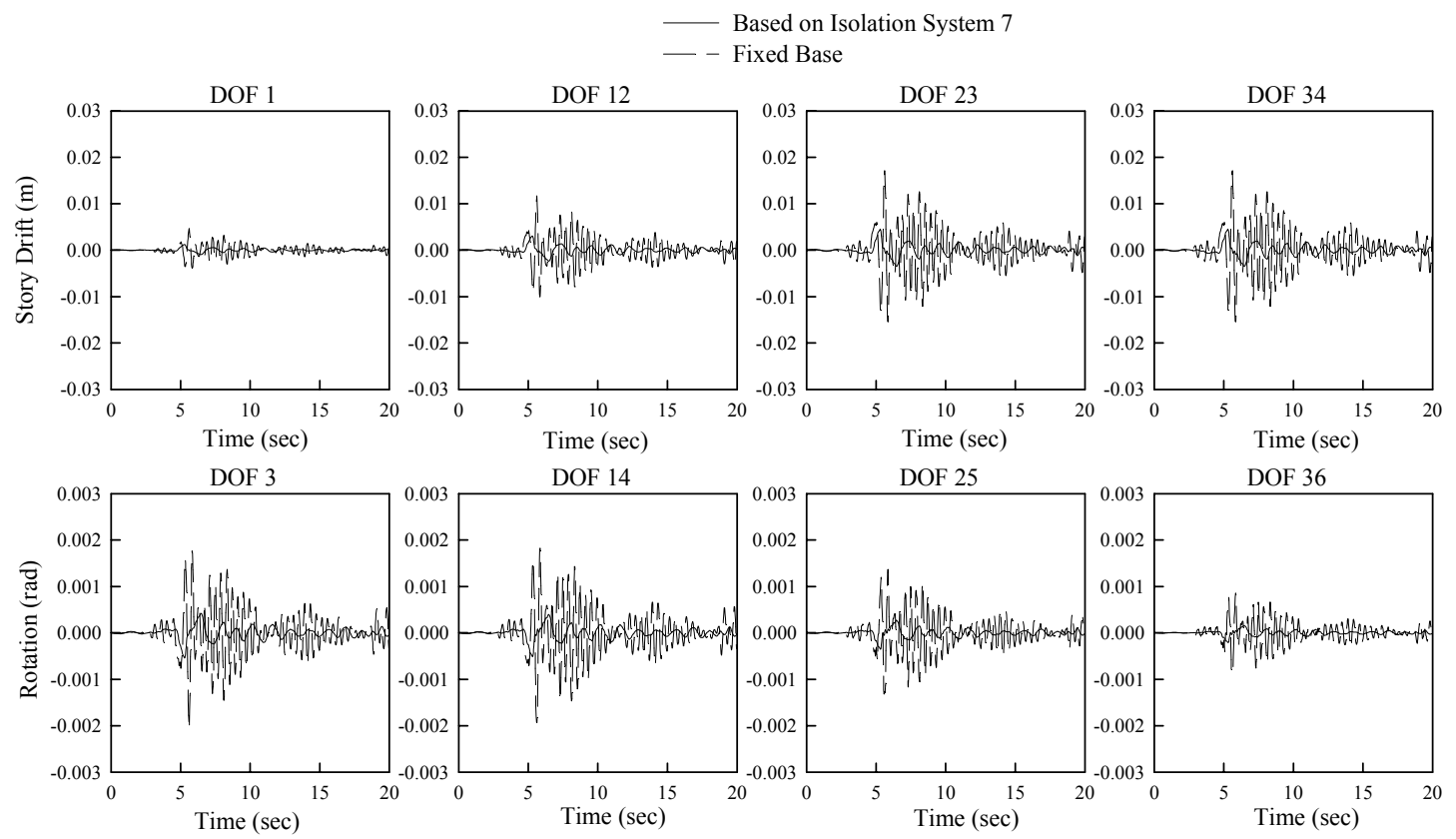

Figure 4: Time Histories of Selected DOF Deformations of Four-story Building (B2) Subjected to the Scaled 1992 Cape Mendocino Earthquake, Petrolia. 
The next point to be investigated was the effect of the superstructure/isolation model on the seismic performance of the isolation system itself. Figure 5 shows the bearing sheardisplacement hysteretic loops of all buildings rested on the isolation system type number 7 which has an effective period of 2.5 seconds and is subjected to the scaled 1979 Imperial Valley earthquake, Array\#7. The figure shows that as the weight of the superstructure increases, the maximum bearing shear increases but the maximum bearing displacement is kept almost the same for all superstructures in spite of the fact that the fundamental period of the fixed base case of each one increases considerably from 0.2 seconds to 0.8 seconds.
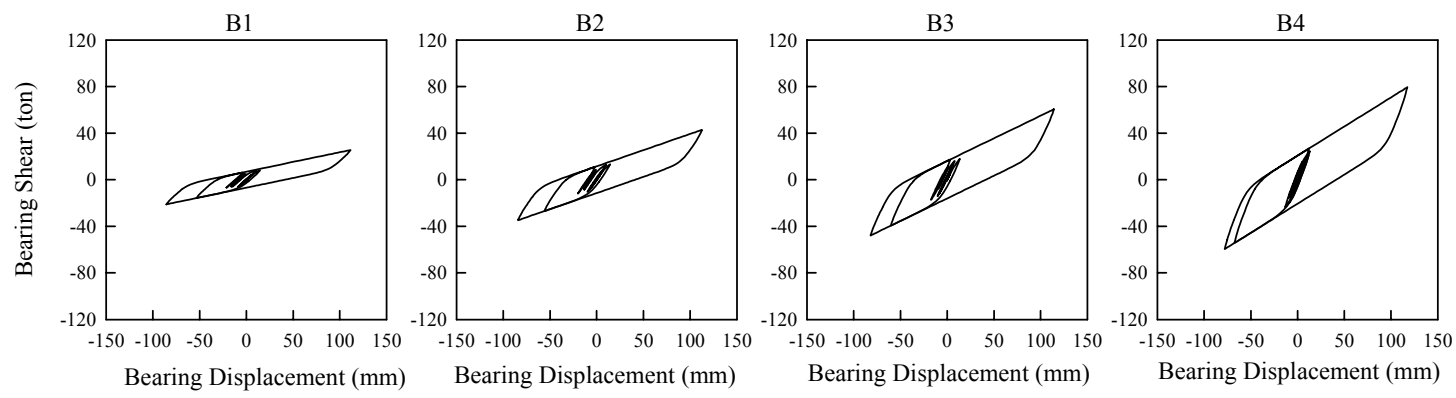

Figure 5: Bearing Shear-Displacement Hysteretic Loops of Various Buildings Based on Isolation System 7 and Subjected to the Scaled 1979 Imperial Valley Earthquake, Array \#7.

On the other hand, Fig. 6 shows the bearing shear-displacement hysteretic loops of the fourstory building (B2) with 0.4 seconds as the fixed base fundamental period based on various isolation systems and subjected to the scaled 1989 Loma Prieta earthquake, Capitola. The figure shows the significance of changing the properties of the isolation system itself and keeping the superstructure mass and stiffness the same on the hysteretic loops. It is quite obvious that as the effective period of the isolation system increases the maximum bearing shear decreases considerably. Furthermore, it is worthy to consider the effect of excitation characteristics on the hysteretic loops when the case of building (B2) on isolation system number 7 are compared with each other in Figs. 5 and 6 as it was subjected to different ground motions. This note reflects the importance of using a set of ground motions as mentioned in most seismic codes instead of using only one or two earthquake time histories.
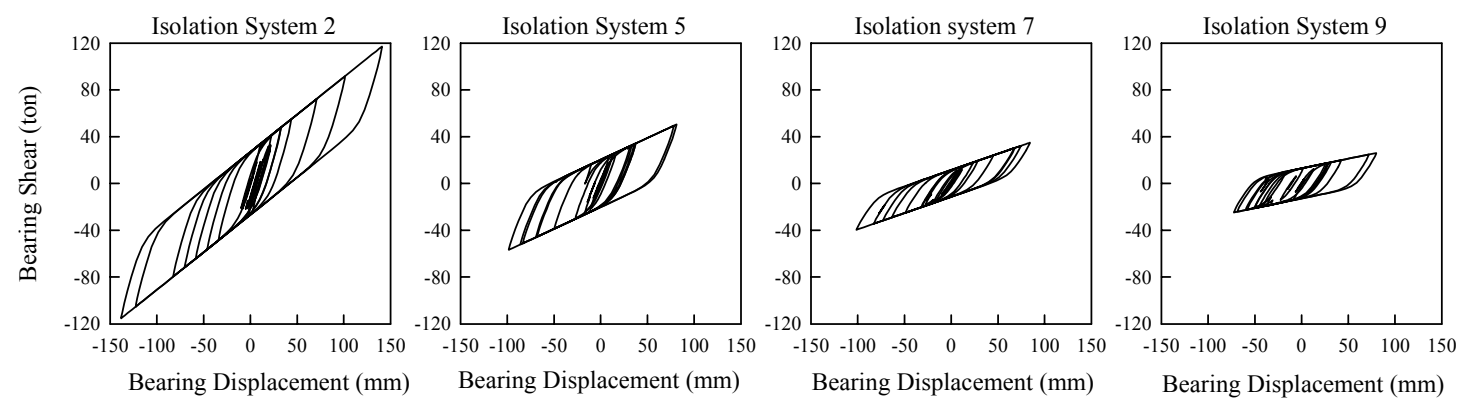

Figure 6: Bearing Shear-Displacement Hysteretic Loops of Building (B2) Based on Various Isolation Systems and Subjected to the Scaled 1989 Loma Prieta Earthquake, Capitola. 
Next, the seismic performance of the four buildings based on some selected isolation systems (number 2, 5, 7 and 9) is presented in Fig. 7, where the story drift relative to the base, story index, story force and story shear distributions along the height are plotted. Each isolation system of interest is selected as a representative for its group. It is quite clear that as the effective period increases, the response increases for most of the considered cases. In addition, the figure shows that the distribution of story forces along the height for the short (2story) building is not linear as most seismic codes recommend for equivalent static analysis [15].

Table 2 shows the roof displacements relative to the base along with the base displacements of the 44 building/isolation system combinations. Within each group, the results are comparable to each other for every building depending on the characteristics of each isolation system. In general, in all base isolated cased, the roof displacements are significantly lower than the results of the corresponding fixed base case. On the other hand, the base displacements are intuitively high and that would be too hard to control in many practical situations. It should be noted that as the effective damping increases, the base displacements decrease significantly. The amount of $15 \%$ effective damping is considered as a reasonable figure by many investigators. Furthermore, Fig. 7 and Table 2 show that the roof displacement increases as the height of the building increases for every isolation system of interest.

Table 3 shows the ratio of the base shear with respect to the total weight of the 44 building/isolation system combinations. In the fixed base cases, the ratio of buildings $\mathrm{B} 1$ and $\mathrm{B} 4$ are lower than those of $\mathrm{B} 2$ and $\mathrm{B} 3$ which is a result of the dynamic interaction between the frequencies of the buildings and the frequency content of the selected earthquake time histories. For some buildings, the responses are higher than the corresponding of the shorter and taller ones as well. On the contrary, for base isolated cases of groups III and IV, the base shear ratios are almost the same irrespective to the type of the building itself. In such cases, the effective periods of the isolation systems are greater than 3 times the fundamental periods of the buildings. Therefore, the resulting base shear ratios depend only on the effective characteristics of the isolation system, as recommended by seismic codes [15]. On the other hand, results of group I show that the base shear ratios are not the same for buildings which are based on various isolation systems. As a result, in the range where periods of the building and the isolation system are close to each other, the seismic codes require the use of the nonlinear time history analysis. 

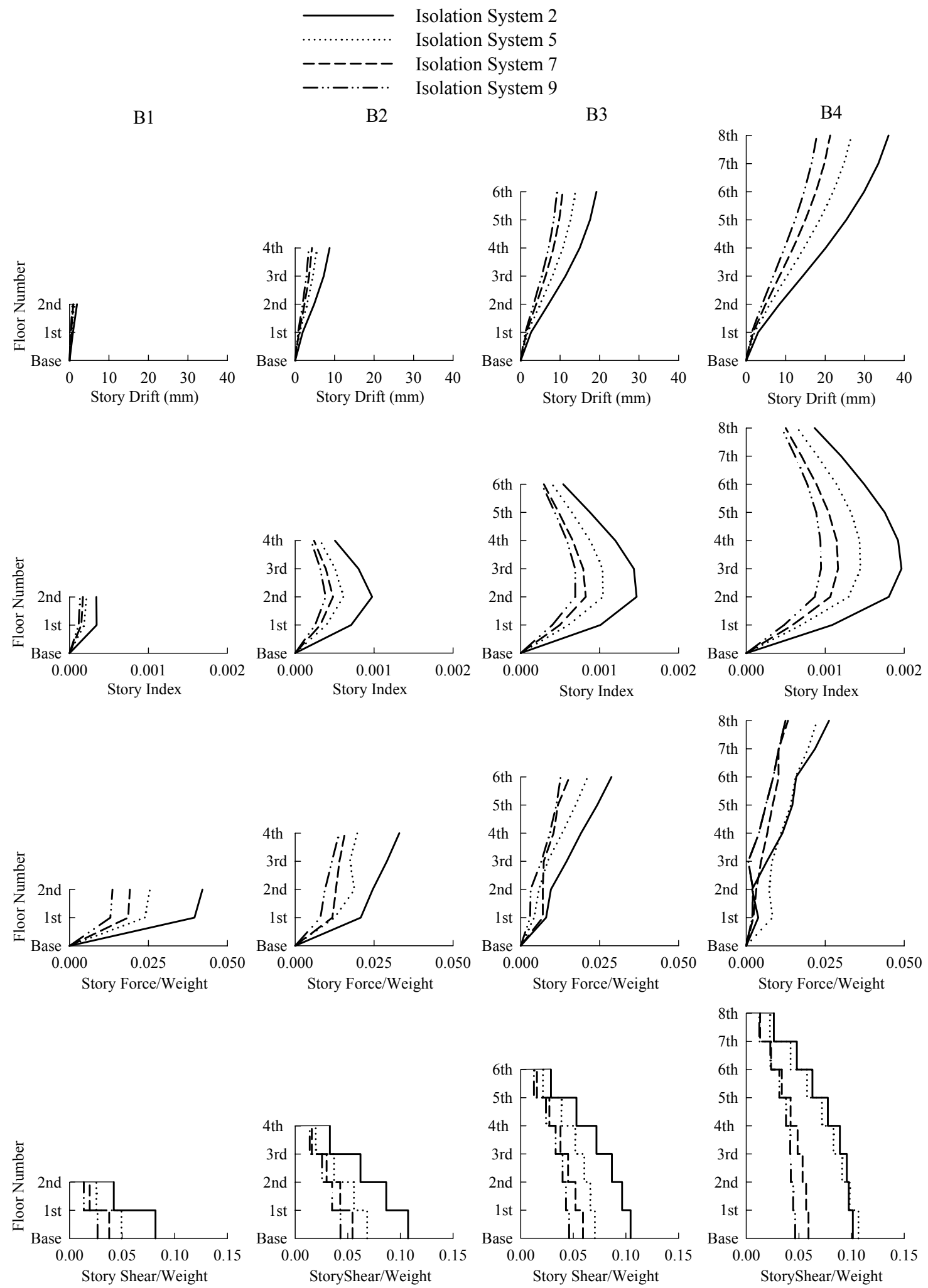

Figure 7: Seismic Performance of the Various Buildings Based on Various Isolation Systems 
Table 2: Roof and Base Displacements for Various Building/Isolation Systems.

\begin{tabular}{|c|c|c|c|c|c|c|c|c|c|}
\hline \multirow{2}{*}{$\begin{array}{c}\text { Group } \\
\text { No }\end{array}$} & \multirow{2}{*}{$\begin{array}{l}\text { Isolation } \\
\text { System }\end{array}$} & \multicolumn{4}{|c|}{ Roof Displacement (mm) } & \multicolumn{4}{|c|}{ Base Displacement (mm) } \\
\hline & & B1 & $\mathrm{B} 2$ & B3 & B4 & B1 & B2 & B3 & B4 \\
\hline \multirow{3}{*}{ I } & 1 & 2.23 & 9.44 & 21.20 & 37.75 & 97.28 & 93.70 & 87.66 & 74.61 \\
\hline & 2 & 1.90 & 8.75 & 19.22 & 36.05 & 77.39 & 74.33 & 70.32 & 62.73 \\
\hline & 3 & 1.70 & 8.86 & 22.06 & 39.88 & 57.90 & 58.45 & 56.57 & 53.44 \\
\hline \multirow{3}{*}{ II } & 4 & 1.30 & 5.62 & 13.55 & 30.83 & 96.34 & 96.24 & 95.44 & 90.92 \\
\hline & 5 & 1.20 & 5.51 & 13.88 & 26.71 & 75.12 & 74.13 & 70.86 & 67.57 \\
\hline & 6 & 1.24 & 12.24 & 16.31 & 30.20 & 73.99 & 65.79 & 65.79 & 64.82 \\
\hline \multirow{2}{*}{ III } & 7 & 0.97 & 4.29 & 10.67 & 21.31 & 99.55 & 99.64 & 98.86 & 99.33 \\
\hline & 8 & 0.92 & 4.57 & 12.61 & 22.69 & 79.87 & 79.14 & 76.14 & 75.49 \\
\hline \multirow{2}{*}{ IV } & 9 & 0.75 & 3.50 & 9.24 & 17.91 & 108.51 & 109.08 & 108.97 & 107.03 \\
\hline & 10 & 0.78 & 4.25 & 11.72 & 22.28 & 87.64 & 87.00 & 84.53 & 84.37 \\
\hline \multicolumn{2}{|c|}{ Fixed } & 6.36 & 34.83 & 69.06 & 96.47 & 0.00 & 0.00 & 0.00 & 0.00 \\
\hline
\end{tabular}

Table 3: Base Shear/Weight Ratios for Various Building/Isolation Systems

\begin{tabular}{||c|c|c|c|c|c||}
\hline \hline $\begin{array}{c}\text { Group } \\
\text { No }\end{array}$ & $\begin{array}{c}\text { Isolation } \\
\text { System }\end{array}$ & $\mathrm{B} 1$ & $\mathrm{~B} 2$ & $\mathrm{~B} 3$ & $\mathrm{~B} 4$ \\
\hline \multirow{3}{*}{ I } & 1 & 0.168 & 0.161 & 0.154 & 0.137 \\
\cline { 2 - 6 } & 2 & 0.148 & 0.144 & 0.137 & 0.122 \\
\cline { 2 - 6 } & 3 & 0.133 & 0.132 & 0.131 & 0.118 \\
\hline \multirow{3}{*}{ II } & 4 & 0.100 & 0.100 & 0.099 & 0.096 \\
\cline { 2 - 6 } & 5 & 0.088 & 0.087 & 0.086 & 0.084 \\
\cline { 2 - 6 } & 6 & 0.093 & 0.091 & 0.088 & 0.085 \\
\hline \multirow{2}{*}{ III } & 7 & 0.075 & 0.076 & 0.075 & 0.076 \\
\cline { 2 - 6 } & 8 & 0.068 & 0.067 & 0.068 & 0.068 \\
\hline \multirow{2}{*}{ IV } & 9 & 0.061 & 0.062 & 0.062 & 0.061 \\
\cline { 2 - 6 } & 10 & 0.058 & 0.058 & 0.058 & 0.058 \\
\hline \multicolumn{2}{|c|}{ Fixed } & 0.252 & 0.376 & 0.396 & 0.296 \\
\hline \hline
\end{tabular}

\section{CONCLUSIONS}

The seismic performance of MDOF isolated structures has been investigated. A computer program has been developed which has the capability of using an efficient nonlinear mathematical algorithm. A set of seven scaled earthquake records has been applied at the base of the system. Based on the present study, the following conclusions can be deduced.

1- Elongating the isolation period away from the fixed base fundamental period, the isolated structure would have lower shear forces and drift displacements at the expense of larger isolation system displacements.

2- For higher buildings with fundamental periods greater than $1 / 3$ of the effective isolation system period, it is recommended to use the nonlinear time history analysis as required by seismic codes.

3- The story force distribution along the height for two-story buildings (less than four stories) is not linear as recommended by seismic codes.

4- On has to look for an isolation system containing the appropriate characteristics with moderate effective damping in order to have better control on the base and superstructure responses. 


\section{REFERENCES}

[1] Naeim, F., and Kelly, J.M. (1999), "Design of Seismic Isolated Structures: From Theory to Practice", John Wiley \& Sons, Inc.

[2] Kelly, J.M. (1990), "Base Isolation: Linear Theory and Design", Journal of Earthquake Spectra, Vol.6, No.2, pp.223-244.

[3] Kircher, C.A. and Lashkari, B. (1989), "Statistical Evaluation of nonlinear Response of Seismic Isolation Systems", Report No. JBA 109-070, jack R. Benjamin and Associates, Inc., Mountain View, CA.

[4] Winters, C.W., and Constantinou, M.C. (1993), "Evaluation of Static and Response Spectrum Analysis Procedures of SEAOC/UBC for Seismic Isolated Structures", Technical Report No. NCEER-93-0004, State University of New York at Buffalo, NY.

[5] Thakkar, S.K., and Jain, S.K. (2004), "Optimum Damping in Isolation System", Proceedings of the 13th World Conference on Earthquake Engineering, Vancouver, Paper No. 1919.

[6] Shi, W., Sun, H., and Wang, Q. (2004), "A Study on Combined Isolation System", Proceedings of the 13th World Conference on Earthquake Engineering, Vancouver, Paper No. 2232.

[7] Megahed, H. and Khafagi, A.A. (2005), "Influence of Energy Dissipation Mechanisms on Seismic Response of Isolated Structures", Eleventh International Colloquium on Structural and Geotechnical Engineering, Ain Shams University, Cairo.

[8] Paz, M. (1985), "Structural Dynamics Theory and Computation", Van Nostrand Reinhold Company Inc.

[9] Applied Technology Council (1993), Proceedings of ATC-17-1 Seminar on Seismic Isolation, Passive Energy Dissipation, and Active Control, Palo Alto, CA.

[10] Applied Technology Council (1996), "Seismic Evaluation and Retrofit of Concrete Buildings", ATC-40, Palo Alto, CA.

[11] Egyptian Code for Loads and Forces in Structural Works and Building Works (2003), Ministry of Housing, Infrastructures and Urban Communities, ECL No.201, Cairo.

[12] Structural Engineers Association of California (1990), Recommended Lateral Force Requirements and Commentary (Blue Book), Seismology Committee, San Francisco, CA.

[13] Tsopelas, P.C., Nagarajaiah, S., Constantinou, M.C., and Reinhorn, A.M., (1991), "3DBASIS-M, Nonlinear Dynamic Analysis of Multiple Building Base Isolated Structures", Technical Report No. NCEER-91-0014, State University of New York at Buffalo, NY.

[14] Wilson, E. and Habibullah, A. (2005), "Structure Analysis Programs- SAP2000 Advanced C 9.1.0", Computer and Structures, Inc. Berkeley, CA.

[15] International Building Code (2003), Structural Design Provisions, IBC 2003, International Code Council, Inc., Falls Church, VA. 